\title{
Epistemological risk aspects
}

\author{
I.B. Ardashkin ${ }^{1 a}$, L.A. Korobeynikova ${ }^{2}$, E.A. Kirsanova ${ }^{3}$, A.V. Kudryashova ${ }^{4}$ \\ 1,3,4 Tomsk Polytechnic University, 634050 Lenin Avenue, 30, Tomsk, Russia \\ ${ }^{2}$ Tomsk State University, 634050 Lenin Avenue, 36, Tomsk, Russia
}

\begin{abstract}
The paper considers risk in the context of the main characteristics of non-classical epistemology. It states that non-classical epistemology is characterized by transformation, according to which the major priority of cognitive activity shifts the focus from the present to the past. In this situation a subject is keen not on what he or she has learnt but on what can be learnt. Truth being a crucial criterion of scientific knowledge is becoming of less priority, while risk is becoming more and more significant and acts as one of the major epistemology measurements. Risk is gaining the status of epistemological phenomenon, which shows a growing degree of uncertainty as a cognitive process background and the necessity for a subject to learn the world (make decisions) under the conditions of uncertainty degree strengthening. The author states that risk is a comprehensive notion and it obtains a base value for all other aspects of its application, specifically, in the role of epistemological phenomenon.
\end{abstract}

\section{Introduction}

Nowadays, epistemology as a branch of philosophy is in the state of transformation. The essence of transformation is that it has not obtained any distinct outline and is in the state of uncertainty. It is more accurate to say that epistemology is represented by a diverse realm of approaches, the correlation of which is not possible (evolutionary epistemology, social epistemology, constructivist epistemology, etc.). Nevertheless, some scientists (V.A. Lektorskij, U.S. Morkina, etc.) suppose that the majority of epistemological approaches can be united by a number of characteristics (which will be discussed later in the paper) and presented as non-classical epistemology being a system of the most characteristic features and tendencies of the whole variety of epistemological branches.

This idea is supported by some reasons, and one of them is the following: the core epistemological issue is the issue on knowledge as a human activity phenomenon. The approaches to studying the nature of knowledge have become more diverse and gained the touch of novelty and unconventionality. According to V.A. Lektorskij, non-classical epistemology is not only a new stage in epistemology development, but also a new way of understanding reality and human nature. Nonclassical epistemology provides a new field for research, particularly important for understanding modern social and cultural processes [1].

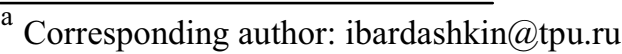

Within this framework, finding new aspects of arranging and understanding cognitive activity as well as specifying the features of humans' cognitive activity will be considered rather natural. Appealing to risk, which the author suggests to view as an epistemological phenomenon, is a sociocultural novelty concerning nonclassical representation of cognitive activity $[2,3,4]$.

\section{The Results and discussion}

Initially, risk was not connected to cognitive activity but was associated with trade and finance. G. Behmann states that the notions of uncertainty and risk appeared in the Middle Ages with regard to the doctrine of usury [5]. Later, the notion gained other meanings, which further have led to the representation expressing hope to overcome the uncertainties of the future. According to G. Behmann, at the end of XVI century the notion "risk" lost its religious meaning (the irreligion risk was connected with a high risk of ruining the sole for the future) and gained a pure economic one. Marine navigation and trade in distant countries created social contexts based on situations of risk. Risk (from Italian "riscare" - "to weigh") denotes, in this case, the opportunity to face uncertain and dangerous future [5].

The economic component of risk in the form of potential threat for the goods, assets, production rapidly gained a social characteristic as well, due to the fast industrial production development [6]. However, the notion of risk did not enter the field of epistemology, while the core concepts of the classical epistemology 
period were presented by objectiveness, truth, science centralism. And, such characteristics of knowledge and cognitive activity had to assure the result (knowledge) reliability, and eliminated any mistake and failure from a subject. Factually, these cognitive activity criteria guaranteed non-obtainment of a dangerous and unreliable result.

Modern society is a different matter, while it needs a lot of metaphors to characterize its diversity: postindustrial society, knowledge society, information society, risk society, etc. The metaphors themselves indicate multistructurality of such society and the nature of processes in it. Nowadays, there is a tendency to sophisticate a lifestyle pattern in terms of both social and natural aspects. This sophistication causes the increased uncertainty in the world perception of individuals and society, disrupts the conventional attitudes and the methods of developing the knowledge of the world. In the circumstances, not only epistemology but also other social systems find themselves in this uncertain situation. Actually, even education, being a social institution, which is, as a rule, the most conservative component of the social body, is constrained to reconsider its aims and means of functioning.

Epistemology itself undergoes considerable changes as well as the other fields of science, philosophy and knowledge do. The cognition of a modern man has reached the highest level and its further development towards cognitive activity requires a considerable foundation of equipment, finance, public support, etc. Nowadays, it is not enough for a scientist to have a purely theoretical interest, which was sufficient for cognitive activity in the age of classical science. To set up a fundamental scientific research it is necessary to unite and motivate many people who may possibly have incomplete understanding of cognitive activity but are indispensable for carrying out the research. This side of social practice does not directly concern epistemological aspect but plays an important role in cognitive activity development.

Moreover, under the present conditions of initiating any applied research, a customer can demand the desirable outcome, setting aside substantive and organizational aspects of cognition. The experience of conducting applied research has shown that scientists are bound to do everything possible to obtain this outcome. It is apparent that such processes in the sphere of cognition do not contribute to its stability. Thus, every epistemological practice requires special interpretation. Not accidentally, some researchers state that the truth in present epistemology is undervalued; therefore, it is impossible to attempt to ascribe a cognitive outcome to a single factor, which is implied by the notion of truth. This situation is caused by the complexity of the modern world. Therefore, the diversity of developing epistemologies assumes that each of them is oriented to understanding of one of the world's constituent parts. It is natural that in this situation uncertainty as a state of knowledge is a rather significant element of any cognitive context.

For greater systemization of non-classical epistemology characteristics let us analyze its very characteristics, which underline the specificity of the modern situation. Particularly, addressing the outcomes of non-classical epistemology by U.S. Morkina appears to be rather appropriate while she carried out significant analysis of the approaches to non-classical epistemology estimation and revealed 21 characteristics of the latter. The following features of non-classical epistemology prove the importance of measuring cognition by means of risk: 1) the world of natural phenomena does not exist apart from observers and their knowledge - it is subjective; 2) world characteristics depend on the observer's priorities and interests; 4) scientific knowledge does not reveal or store the outer world genuine features; 9) scientific knowledge implies the physical world description mediated by various cultural resources; 15) scientific knowledge is not an epistemologically privileged knowledge case; 18) rejection of fundamentalism; 20) rejection of science centralism [7].

As the given characteristics show, cognitive activity in non-classical epistemology is treated as a complex and diverse process not adhere to any versatile constants. Besides, the role of a subject (an individual or a group) is becoming important; their role in cognition and the degree of presence in knowledge is increasing. But it should be mentioned that a considerable influence of a subject on the cognition process should not be connected with solipsism. If in the latter the world is, factually, the subject's own construction, the subject's activity in nonclassical epistemology is conditioned by the world order complexity, speed of processes, globalization, and the complementary knowledge specialization. Today, a single person is unable to act as a universal specialist with the required potential. The humanity and science face global problems, cognition of which is beyond a single person ability (moreover, everyday problems should be solved as well). To understand and solve such problems the efforts of various research teams from different fields of knowledge are required together with the necessity to involve the efforts of states and the world community.

It is not a coincidence that the role of an expert form of cognitive activity has become reinforced. Frequently, a researcher does not have an opportunity to clearly justify the choice of one or another solution. In this case it is rather natural for the researcher to use expert evaluation. To provide the given technique with a clearer solution, the scientists strive for attracting the widest possible range of experts from different fields of knowledge, which makes a complex solution even more complicated. As L.A. Mikeshina states, since evaluation is always subjective and depends on the peculiarities and purposes of the subject who makes it, modern methods of attracting experts seek to provide a more fully engagement of specialists of different profiles, their selection improvement and evaluations harmonization. Great importance is attached to the procedure aimed at reducing the psychological influence of the reasons decreasing expert solutions effectiveness, among which are mutual persuasion, authorities influence, etc. [8].

But the most important thing is that greater involvement of experts (not only scientist) leads to the 
intersection of various social being measurements: cognitive, social, cultural, natural, etc. According to L.A. Mikeshina, the methods of expert evaluations make the system of techniques for scientific and technical problems solution more flexible and optimal, and also act as the channels for the penetration of politico-social, culture-historical, socio-psychological factors into the essence of scientific and technical knowledge gained in the process of problem solving [8].

The scope of the specialists involved increases not only the opportunities to find effective solutions, but also the degree of uncertainty and risk. On the one hand, risk has social genesis while the consequences of solutions for the society and individual are considered, and, on the other hand, risk is closely connected with cognition while the possible consequences are based on someone's subjective solution. Actually, epistemological risk measurement indicates the indivisibility of the social factor and scientific cognition. U. Bek pointed out that claims of scientific rationality concerning the objective definition of the level of risk in dangerous situations constantly contradict themselves while they are based on the house of cards of speculations and range only inside probability statements; security prospects contained in them cannot be refuted even by actual accidents [9].

Risk appears to be an essential measurement of cognitive activity not only due to the application of expert evaluation. Risk acts as an integral part of an individual's world perception. When the world perception (cognition) is presented as a process, in the scope of which a person takes decisions, different degrees of uncertainty initiate risk like a mechanism of finding solutions under the conditions of complete clarity absence. The smaller such clarity is, the more responsibility will be imposed on a subject (person), and, consequently, when making choice a person forms such measurement of one's own activity (and cognition as well) as risk. As V.S. Diev states, risk is the solution outcome and is always connected with the subject who not only makes choice but also considers the probability of possible events and losses connected with it. Risk is an integrated index combining the evaluations of solutions probability and the quantitative characteristics of its consequences as well [10].

Risk does exist in cognition while it is connected with a subject and represents the limitation of his/her heuristic choice. This complexity is revealed in the situations when a subject has not made a choice yet and there is a wide range of possible options to be chosen, he or she, actually, has to risk and make choice. Moreover, having made such choice the subject merely specifies risk. And, herein lies the peculiarity of cognitive activity in non-classical epistemology: risk should be specified. It cannot be eliminated but is possible to be specified. In this case the subject has a clearer vision of one or another decision outcome and, therefore, can evaluate epistemological consequences better.

Essentially, in such situations a subject must choose one uncertainty from the range of possible ones. It means that the researcher will make the choice only in the scope of the sphere he feels to be concerned with. But, considering the fact that a researcher (a team of researchers) faces the global problem (and this is the kind of problems non-classical epistemology is distinguished by), he or she will be more likely to narrow the sphere of his/her uncertainty by the desire to proceed in cognition, while there is rather little probability to obtain full clarity. G. Behmann presented such kind of processes in the following way: the development of physics precisely reflects this phenomenon. Reasoning on the linear worldview of classical physics, which can keep the complexity of macroscopic natural phenomena to the simple structures of microworld, is split by the universum of modern physics' supercomplex relationships [5]. Then, G. Behmann specifies that there is no unified perspective of such kind to fit the topic within the limits that are definite and acceptable by everyone [5].

Uncertainty as the background for cognitive activity appears as an irremovable component due to the active participation of a subject (subjects). The subject will inevitably execute a cognitive operation under these conditions; uncertainty will not disappear or clarify itself. Thus, risk appears as one more measurement of cognitive activity. In classical science the major priority of scientific research was connected with the truth, while nowadays, whenever strange it may seem, one of the major priorities of scientific cognition is risk. It means that the truth as the criterion for scientific cognition measurement is entirely eliminated, which means that, firstly, the truth becomes socio-culturally, sociopolitically, socio-economically, etc. engaged nowadays, secondly, the truth can be conditioned by different degrees of risk. And, what is very important, it is the most significant epistemological consequence of cognition in general and scientific consequence in particular.

It should be added that when talking about applied science, the stated peculiarity of cognitive activity becomes even more actual. The development of technologies being implemented into industry and public activity, income orientation, etc. as the priorities of applied scientific research enhance the degree of risk for an individual and the society as a whole while the principles of the scientist's activity are not actually distinguished in the spheres of fundamental and applied research. Essentially, nowadays there is the idea of developing technoscience, in which epistemological and technological components will be strongly connected. Fundamental research is impossible to be conducted with the lack of the suitable equipment and technology and it is rather difficult to develop technology without fundamental research. A scientist in this kind of research acts as a visionary or a foreteller, whose statements seem unexpected for people. It is rather interesting what $\mathrm{G}$. Behmann compares scientific research with, when he states that modern science acts as a doer, as Cassandra taking measures [6].

It is obvious that a scientist in such conditions is involved in cognition activity, takes the risk. Furthermore, it is clear that the society, which allows scientists to participate in cognition activity under such conditions, takes more risk taking into account the 
probable consequences of technical research results application. It is the reason why the authors want to indicate the problem of risk as an epistemological phenomenon in non-classical epistemology, while it is the epistemological side of risk, which is invisible but, therefore, more dangerous for the society.

Risk is a multidimensional phenomenon: social, political, economic, legal, technological, etc [11]. But, as a rule, many risks can be specified and figured out. Economic risk can be calculated and evaluated, technological risk can be detailed and warned via instructions, it is possible to hedge against risk by law, etc. But in case of epistemological risk it is rather difficult to be anticipated, hedged, while it is impossible to regulate a mental activity stream.

From the point of view of cognition, control over one's own reflection is possible only on the basis of selfcontrol. A researcher should realize the degree of responsibility to the world and society in order to evaluate probable negative outcomes of his/her own ideas. In addition, it should be mentioned that risk as the measurement of human life and activities, and society functioning (including the epistemological aspect) does not necessarily imply negative outcomes. The essence of risk is connected to the fact that a person decides to take definite actions in situations of uncertainty in order to achieve a positive result. And, as he or she acts without clear understanding of all situation aspects, first of all, an epistemological one, the factor of risk appears as the factor of uncertainty enhancement. To illustrate the idea, the example with mass distribution of mobile telephony in our country can be drawn. Actually, the process began 10 or 11 years ago (in $2002-2003$ ). Today we frequently hear about potential threats to the health caused by a mobile phone in case of its improper use (hearing impairment, negative effect of electromagnetic phone on the brains, etc.).

Risk appears when people race ahead too quick, focus on the future but not the present time. Otherwise, there would be no risk. People (society) tend to follow this proverb: go I know not whither and fetch I know not what. The most important is that initially this process is carried out epistemologically. According to E. Giddens, traditional cultures did not contain the notion of risk because they did not need it. Risk is not the same as danger or threat. The notion of risk is connected with active analyzing the danger from the view of the future outcomes. It is widely used only in the society oriented at the future and which perceives it as the territory to be conquered and colonized [12].

Society directed to the future, primarily needs the epistemologies of this kind (these are the main essence of non-classical epistemology and its major characteristics). This causes the decreased interest in the truth (the latter characterizes the quality of knowledge about the present moment reality). And it is the reason of the epistemological fields diversity (there are no rigid criteria of cognitive activity; it is considered either as constructivist activity or evolutionary transformation, or project activities, etc.). As V.G. Gorohov so deftly pointed out, the role of science in the modern society of "no-knowledge" is being changed relatively to the processes of risk formation [13]. And it is hard not to agree to V.G. Gorohov while the world is becoming more complex and we continue to live in it with a larger uncertainty.

The degree of uncertainty (its growth) is better seen in the situation of specifying more and more risks with the growing role of a person. In particular, Australian researcher C. Althaus considered the perspectives of the epistemological risk aspect study and specified 5 types of risk. In three of them, understanding of the conditions for their originating and functioning were connected with the human factor and the decisions a human makes. The researcher distinguishes the following types of risk: subjective risk (psychological state of a person who feels uncertainty, doubt or anxiety about the result); objective risk (changes which happen when actual losses differ from the expected ones); actual risk (the combination of probable and negative consequences existing in the real world); observed risk (measuring the combination gained by creating a model of the real world); perceptive risk (rough evaluation of actual risk made by untrained society member) [14].

As we can judge from the given characteristics, at least subjective, observed and perceptive risks are conditioned by subjective reasons and depend on humans' decisions. Probably, objective and actual risks are conditioned by this kind of connections as well. Concerning objective risk, such dependence is connected with the evaluation of the expected losses (it deals with the subjective construction); in case of actual risk we are talking about the dependence of probabilities and negative outcomes when they are combined by the subject.

An additional point is that epistemological nature of risk can be conditioned by the diversity of risks and, consequently, the necessity of evaluating and choosing them. The variety of risks and the necessity to choose the most suitable ones originate epistemological uncertainty. Thus, there is the necessity of risk as an inevitable condition of the epistemological strategy of a non-classical type.

Actually, if we go back to the non-classical epistemology characteristics specified by U.S. Morkina given above in the paper, it becomes obvious that primarily these characteristics define epistemology as the process of the risky organization of cognitive activity while these are the subjective decisions it is made through. For example, the world of natural phenomena does not exist independently of an observer and our knowledge about it is subjective; scientific knowledge does not discover or store the genuine features of the outer world; scientific knowledge implies a kind of physical world description mediated by various cultural resources, etc. As it is clear from these characteristics, it is impossible to avoid a subject's participation (and, therefore, his or her process of decision making), which originates risk as an epistemological phenomenon.

\section{Conclusion}

Thus, it should be stated that in the context of nonclassical epistemology risk becomes not only the specified condition for cognitive activity but also the characteristic distinguishing classical epistemology from 
non-classical one. The most important thing risk incorporates as an epistemological phenomenon is the situation of uncertainty specified by the subject for the fastest possible overcoming of the present moment society development. The development speed and the desire to get "there" as rapidly as possible originate risk as a subjective epistemological strategy of searching something new and unknown. The possibility of gaining this result is connected with risk, but the loss of hope can lead to rather serious threats, but it is what the ambivalence of risk and the epistemological aspect of risk as a kind of cognitive ground for a subject all about.

\section{Acknowledgment}

The article is supported by the Russian Humanitarian Science Foundation grant № 16-16-70006.

\section{References}

1. V.A. Lektorskij, Na puti $k$ neklassicheskoj 'epistemologii. (IFRAN, Moscow, 2009)

2. P. Tychkin, Proc. Soc. and Beh. Sc., 166 (2015)

3. M. Goncharenko, Proc. Soc. and Beh. Sc., 166 (2015)

4. A. Chmykhalo, M. Abushaeva, Proc. Soc. and Beh. Sc., 166 (2015)

5. G. Behmann, Sovremennoe obschestvo: obschestvo riska, informacionnoe obschestvo, obschestvo znanij. (Logos, Moscow, 2012)

6. I.B. Ardashkin, A.N. Yakovlev, N.V. Martyushev, Adv. Mat. Res., 1040 (2014)

7. Yu.S. Morkina, Filos. Zhurn., 1 (2011)

8. L.A. Mikeshina, 'Epistemologiya cennostej (Rossijskaya politicheskaya 'enciklopediya, Moscow, 2007)

9. U. Bek, Obschestvo riska: Na puti $k$ drugomu modern (Progress-Tradiciya, Moscow, 2000)

10. V.S. Diev, Vest. Tomsk. Gosud. Univ., filos., social., polit., 2 (22) (2013)

11. M. A. Makienko, A. N. Panamareva, Proc. Soc. and Beh. Sc., 166 (2015)

12. E. Giddens, Uskol'zayuschij mir: kak globalizaciya menyaet nashu zhizn (Ves mir, Moscow, 2004)

13. V.G. Gorohov, Vvodnaya stat'ya. Behmann $G$. Sovremennoe obschestvo: obschestvo riska, informacionnoe obschestvo, obschestvo znanij (Logos, Moscow, 2012)

14. Catherine E. Althaus, Risk Anal., 3 (25) (2005) 